\title{
Ocular Injuries Caused by Intimate Partner Violence Using an Emergency Room Database - A Gender - Based Analysis
}

\section{Radhika Malhotra, Yash S Shah, Paul D Langer and Neelakshi Bhagat* \\ Department of Ophthalmology. Rutgers New Jersey Medical School, Newark, NJ, $U S A$}

*Corresponding Author: Neelakshi Bhagat, Department of Ophthalmology. Rutgers New Jersey Medical School, Newark, NJ, USA.

DOI: 10.31080/ASOP.2022.05.0469
Received: February 08, 2022

Published: February 18, 2022

(C) All rights are reserved by Neelakshi

Bhagat, et al.

\begin{abstract}
Objective: Intimate partner violence (IPV) has increased since the start of the COVID-19 pandemic. Ophthalmologists and emergency department (ED) physicians should be vigilant in assessing patients with ocular injuries for a history of IPV. Our study is aimed to describe the epidemiology of patients presenting to the emergency department with ocular injuries secondary to IPV.

Methods: We conducted a retrospective study using the National Electronic Injury Surveillance System-All Injury Program (NEISSAIP) from 2006 to 2016 in 60 emergency departments across the United States. 25,541 ED patients with an ocular injury due to IPV were analyzed. Main outcomes included race, hospital size, incident location, reason for assault, precipitating cause of injury, and medical diagnosis.

Results: IPV-related ocular injuries were more commonly noted in women compared to men (73.8\% vs $26.2 \%)$. Most patients were in the young adult group (21-30 years old). Men and women were primarily Black in majority. In males, the precipitating cause of injury was either being struck by an object or injury by fire (struck $66.1 \%$, fire $30.6 \%$ ), whereas females were overwhelming injured by a striking injury (90.4\%). The most common diagnosis was an ocular contusion or abrasion (males $43.4 \%$ vs females $53.4 \%$ ).

Conclusion and Relevance: IPV results in significant ocular trauma that presents to the ED, and is more commonly see in women, black race, and young adults. However, men can also be victims of IPV and should be equally evaluated. Assessment of IPV is important in ocular injury seen in the ED.
\end{abstract}

Keywords: Intimate Partner Violence; IPV; Ocular Injuries; Eye Trauma

\section{Introduction}

Intimate partner violence (IPV) is defined as "physical or sexual violence, stalking, or aggression by a partner, current or former" by the National Center for Injury Prevention and Control [1]. Women are more likely than men to experience IPV; $1 / 3$ of US women have been affected, particularly at a younger age [2]. Dearwater reported approximately $40 \%$ of female homicides are due to IPV, and half of these cases had presented to the emergency department (ED) within two years prior to death [3].
IPV accounts for $70 \%$ of facial trauma cases in women, and ocular involvement is noted in $45 \%$ of these cases [4]. Previous studies have identified IPV as a significant cause of orbital floor fractures in women [5]. Victims of IPV are likely to visit the ED, but in most cases IPV as the cause of the injury may not be identified [3]. The current literature on IPV-related ocular injuries is scarce. It is important for ED physicians and ophthalmologists to recognize ocular injuries due to IPV in both men and women. The current study aims to determine epidemiologic trends of IPV-related ocular trau- 
Ocular Injuries Caused by Intimate Partner Violence Using an Emergency Room Database - A Gender - Based Analysis

ma presenting to the ED to improve our understanding and to raise awareness of these injuries.

\section{Methods}

The National Electronic Injury Surveillance System-All Injury Program (NEISS-AIP) was queried for injuries specifically involving the eye (variable "eyeball") between 2006 and 2016. The All Injury Program (AIP) samples around 60 hospitals from the overall NEISS dataset to obtain data regarding all injuries presenting to the ED. This data is collected as public information, and available through the Interuniversity Consortium for Political and Social Research (ICPSR) at https://www.icpsr.umich.edu/icpsrweb/ICPSR/ search/studies?q=all+injury+program. The information is deidentified and considered to be exempt by the Rutgers Institutional Review Board.

The data included age and categorical variables including gender, race, hospital size, incident locale, disposition from ED, reason for assault, precipitating cause of injury, and diagnosis (selecting for the anatomic location of the eyeball [code=77]). Data was weighted using the inborne weight variable in the database. Domestic violence was analyzed similar to previous studies using the AIP database [6]. Statistical analysis was completed with IBM Statistical Package for the Social Sciences (SPSS) version 25.0.

\section{Results}

A total of 6,888,197 cases of ocular injury were described in the NEISS database (Table 1 ). Of those, $0.37 \%$ were secondary to intimate partner violence. Between 2006 and 2016, 25,451 ocular injuries as a result of IPV were identified in 6,667 men (26.2\%) and $18,748(73.8 \%)$ women in a ratio of approximately $1: 4$. The average age (in years) of males and females was 36.7 and 32.9, respectively. Demographics are noted in table 2 . The majority of victims, both male and female, were between 21 and 50 years old. The highest proportion of men presenting with ocular injuries due to IPV were Black (47.5\%, $\mathrm{p}<0.001$, Chi-square), a trend that was similar in women (Black women 35.5\%, p < 0.001).

\begin{tabular}{|c|c|c|}
\hline $\begin{array}{c}\text { Ocular injuries in } \\
\text { NEISS database }\end{array}$ & \multicolumn{2}{|c|}{$6,888,197$} \\
\hline $\begin{array}{c}\text { Ocular injuries } \\
\text { secondary to IPV }\end{array}$ & \multicolumn{2}{|c|}{$25415(0.37 \%)$} \\
\hline & Male & Female \\
\hline
\end{tabular}

\begin{tabular}{|c|c|c|}
\hline Ocular cases & $4,675,649$ & $2,207,395$ \\
\hline Mean age (years) & $36.64(27.1)$ & $39.28(34.7)$ \\
\hline \multicolumn{3}{|c|}{ Race } \\
\hline Unknown & $1,114,446(23.8 \%)$ & $\begin{array}{l}505,858 \\
(22.9 \%)\end{array}$ \\
\hline White & $2,683,615(57.4 \%)$ & $\begin{array}{c}1,157,909 \\
(52.5 \%)\end{array}$ \\
\hline Black & 405,067 (8.7\%) & $\begin{array}{l}334,382 \\
(15.1 \%)\end{array}$ \\
\hline Hispanic & $392,201 * 8.4 \%)$ & $\begin{array}{c}150,040 \\
(6.8 \%)\end{array}$ \\
\hline Asian & $47,353(1.0 \%)$ & $\begin{array}{l}37,182 \\
(1.7 \%)\end{array}$ \\
\hline American Indian & $15,503(0.3 \%)$ & $\begin{array}{l}12,497 \\
(0.6 \%)\end{array}$ \\
\hline Other & $409,665(8.8 \%)$ & $\begin{array}{c}159,840 \\
(7.2 \%)\end{array}$ \\
\hline
\end{tabular}

Table 1: Ocular injuries in NEISS database and demographics.

\begin{tabular}{|c|c|c|c|}
\hline & Male & Female & p-value \\
\hline $\begin{array}{l}\text { Number of } \\
\text { cases }\end{array}$ & $6667(26.2 \%)$ & $18748(73.8 \%)$ & \\
\hline $\begin{array}{l}\text { Mean age } \\
\text { (years) }\end{array}$ & 36.68 (12.38) & 32.78 (11.27) & $\mathrm{P}<0.001$ \\
\hline \multicolumn{4}{|l|}{ Race } \\
\hline Unknown & $1623(24.3 \%)$ & $4701(25.1 \%)$ & \multirow[t]{7}{*}{$\mathrm{P}<0.001$} \\
\hline White & 1205 (18.1\%) & $5094(27.2 \%)$ & \\
\hline Black & 3165 (47.5\%) & $6663(35.5 \%)$ & \\
\hline Hispanic & $590(8.8 \%)$ & 1547 (8.3\%) & \\
\hline Asian & $0(0 \%)$ & $406(2.2 \%)$ & \\
\hline $\begin{array}{l}\text { American } \\
\text { Indian }\end{array}$ & $84(1.3 \%)$ & $133(0.7 \%)$ & \\
\hline Other & & & \\
\hline \multicolumn{4}{|c|}{ Hospital Size } \\
\hline Small & $893(13.4 \%)$ & $1815(9.7 \%)$ & \multirow[t]{5}{*}{$P<0.001$} \\
\hline Medium & $1343(20.1 \%)$ & 3383 (18\%) & \\
\hline Large & $2472(37.1 \%)$ & $6880(36.7 \%)$ & \\
\hline Very large & 1957 (29.4\%) & $6631(35.4 \%)$ & \\
\hline Children's & $0(0 \%)$ & $39(0.2 \%)$ & \\
\hline \multicolumn{4}{|c|}{ Incident Locale } \\
\hline
\end{tabular}


Ocular Injuries Caused by Intimate Partner Violence Using an Emergency Room Database - A Gender - Based Analysis

\begin{tabular}{|c|c|c|c|}
\hline Unknown & $3347(50.2 \%)$ & $10079(53.8 \%)$ & \multirow[t]{4}{*}{$\mathrm{P}<0.001$} \\
\hline Home & $3161(47.4 \%)$ & $8113(43.3 \%)$ & \\
\hline Street & $113(1.7 \%)$ & $251(1.3 \%)$ & \\
\hline Property & $46(0.7 \%)$ & $305(1.6 \%)$ & \\
\hline \multicolumn{4}{|c|}{ Disposition from ED } \\
\hline Released & $5829(87.4 \%)$ & $17129(91.4 \%)$ & \multirow[t]{5}{*}{$\mathrm{P}<0.001$} \\
\hline Transferred & $139(2.1 \%)$ & $133(0.7 \%)$ & \\
\hline Hospitalized & $273(4.1 \%)$ & $581(3.1 \%)$ & \\
\hline Observation & $85(1.3 \%)$ & $92(0.5 \%)$ & \\
\hline AMA & $341(5.1 \%)$ & $814(4.3 \%)$ & \\
\hline \multicolumn{4}{|c|}{ Reason for Assault } \\
\hline Altercation & $2224(33.4 \%)$ & $3899(20.8 \%)$ & \multirow[t]{5}{*}{$\mathrm{P}<0.001$} \\
\hline Drug-related & $0(0 \%)$ & $44(0.2 \%)$ & \\
\hline Sexual assault & $0(0 \%)$ & $370(2 \%)$ & \\
\hline Other specified & $130(1.9 \%)$ & $296(1.6 \%)$ & \\
\hline $\begin{array}{l}\text { Unknown } \\
\text { unspecified }\end{array}$ & $4313(64.7 \%)$ & $14139(75.4 \%)$ & \\
\hline \multicolumn{4}{|c|}{ Precipitating Cause of Injury } \\
\hline MV-occupant & $0(0 \%)$ & $24(0.1 \%)$ & \multirow[t]{9}{*}{$\mathrm{p}<0.001$} \\
\hline Fall & $0(0 \%)$ & $84(0.4 \%)$ & \\
\hline $\begin{array}{l}\text { Struck by } \\
\text { object }\end{array}$ & $4408(66.1 \%)$ & $16964(90.4 \%)$ & \\
\hline Cut/pierce & $215(3.2 \%)$ & $179(1 \%)$ & \\
\hline Fire/burn & $2043(30.6 \%)$ & $1093(5.8 \%)$ & \\
\hline $\begin{array}{l}\text { Inhalation/ } \\
\text { sufflation }\end{array}$ & $0(0 \%)$ & $102(0.5 \%)$ & \\
\hline Foreign body & $0(0 \%)$ & $197(1.1 \%)$ & \\
\hline $\mathrm{BB} /$ pellut gun & $0(0 \%)$ & $22(0.1 \%)$ & \\
\hline Other specified & $0(0 \%)$ & $84(0.4 \%)$ & \\
\hline \multicolumn{4}{|c|}{ Diagnosis } \\
\hline Burn chemical & $758(11.4 \%)$ & $539(2.9 \%)$ & \multirow[t]{9}{*}{$\mathrm{P}<0.001$} \\
\hline $\begin{array}{l}\text { Contusion/ } \\
\text { abrasion }\end{array}$ & $2890(43.4 \%)$ & 10017 (53.4\%) & \\
\hline Foreign body & $21(0.3 \%)$ & $287(1.5 \%)$ & \\
\hline Hematoma & $49(0.7 \%)$ & $836(4.5 \%)$ & \\
\hline Laceration & $217(3.3 \%)$ & $208(1.1 \%)$ & \\
\hline Puncture & $44(0.7 \%)$ & $0(0 \%)$ & \\
\hline Hemorrhage & $487(7.3 \%)$ & $1223(6.5 \%)$ & \\
\hline Other & $1140(17.1 \%)$ & $4696(25 \%)$ & \\
\hline $\begin{array}{l}\text { Derma/ } \\
\text { conjunctivitis }\end{array}$ & $1061(15.9 \%)$ & $942(5 \%)$ & \\
\hline
\end{tabular}

\begin{tabular}{|c|c|c|c|}
\hline \multicolumn{4}{|c|}{ Day of the Week } \\
\hline Weekday & $\begin{array}{c}4256 \\
(63.85 \%)\end{array}$ & $\begin{array}{c}11563 \\
(61.68 \%)\end{array}$ & \multirow[t]{2}{*}{$\mathrm{P}<0.001$} \\
\hline Weekend & $\begin{array}{c}2410 \\
(36.15 \%)\end{array}$ & $7185(38.32 \%)$ & \\
\hline \multicolumn{4}{|c|}{ Month } \\
\hline January & $516(7.7 \%)$ & $1719(9.2 \%)$ & \multirow[t]{11}{*}{$\mathrm{P}<0.001$} \\
\hline February & $491(7.4 \%)$ & $1111(5.9 \%)$ & \\
\hline March & $366(5.5 \%)$ & $962(5.1 \%)$ & \\
\hline April & $515(7.7 \%)$ & $1063(5.7 \%)$ & \\
\hline May & $510(7.6 \%)$ & $2014(10.7 \%)$ & \\
\hline June & $892(13.4 \%)$ & $1705(9.1 \%)$ & \\
\hline July & 925 (13.9\%) & $1801(9.6 \%)$ & \\
\hline August & $589(8.8 \%)$ & $1681(9.0 \%)$ & \\
\hline September & $1051(15.8 \%)$ & $1903(10.2 \%)$ & \\
\hline October & $154(2.3 \%)$ & $2148(11.5 \%)$ & \\
\hline November & 342 (5.1\%) & $1437(7.7 \%)$ & \\
\hline December & $316(4.7 \%)$ & $1204(6.4 \%)$ & \\
\hline
\end{tabular}

Table 2: Demographics and Precipitating Causes of Ocular Injuries Due to IPV in the ED.

The most common ocular injury was contusion/abrasion (Men $43.4 \%$, women $53.4 \%$, $\mathrm{p}<0.001$ ). Approximately $45 \%$ of incidents occurred at home (men 47.4\%, women $43.3 \%$, $p<0.001$ ). The vast majority of patients were treated and released from the ED (men $87.4 \%$, women $91.4 \%, p<0.001$ ). Fewer than $5 \%$ of patients were hospitalized (men 4.1\%, women 3.1\%, p < 0.001). Upon assessing for the reason for assault, the cause was unknown in the majority of cases (men $64.7 \%$, women $75.4 \%$, p < 0.001), followed by altercation (men 33.4\%, women 20.8\%, p < 0.001). Women were more likely than men to have ocular injury after a reported sexual assault (men $0 \%$, women $2 \%, \mathrm{p}<0.001$ ). For females, the overwhelming precipitating cause of injury was being struck by an object $(90.4 \%$,), whereas in males, the two major causes were being struck by an object (66.1\%) or fire/burns (30.6\%). Distribution of cases in time is shown in table 2; almost one-fourth of cases in women presented to the ED on Sunday.

Table 3 shows a univariate analysis assessing the risk of hospitalization when taking into account race and age - those $>35$ years old were significantly more likely to be hospitalized, in women (OR 2.257, 95\% CI 1.912-2.664, p < 0.001) and men (OR 6.163, 95\% CI 
4.445-8.545, $\mathrm{p}<0.001)$. Blacks with IPV related eye injuries were less likely to be hospitalized than Whites [women (OR 0.593, 95\% CI 0.448-0.873, p < 0.001); men (OR 0.505, 95\% CI 0.385-0.663 p $<0.001)]$.

\begin{tabular}{|l|c|l|c|l|}
\hline & Male & & Female & \\
\hline & OR (95\% CI) & p-value & OR (95\% CI) & p-value \\
\hline Race & & & & \\
\hline White & Ref & & Ref & \\
\hline Black & $\begin{array}{c}0.505 \\
(0.385-0.663)\end{array}$ & $<0.001$ & $\begin{array}{c}0.593 \\
(0.448-0.783)\end{array}$ & $<0.001$ \\
\hline $\begin{array}{l}\text { Age } \\
\text { Group }\end{array}$ & & & & \\
\hline$<35$ & Ref & & Ref & \\
\hline$>35$ & 6.163 & $<0.001$ & $\begin{array}{c}2.257 \\
(1.912-2.664)\end{array}$ & $<0.001$ \\
\hline
\end{tabular}

Table 3: Univariate Analysis by Gender assessing for risk of hospitalization.

\section{Discussion and Conclusion}

Laceration and abrasion have been described as common diagnoses for IPV related ocular injuries, and accidental trauma by an object as the most common etiology [7]. Our study similarly found that in females, the most common precipitating ocular injury was being struck by an object resulting in contusion or abrasion. Although our study does not detail the type of object being used, prior studies have found that household objects are usually seen in these injuries [8]. Contusions, abrasions, and hemorrhages were the most common overall presentations of patients in this study. NEISS-AIP only includes primary diagnoses of patients, but metaanalyses have shown that witnessed head, neck, or facial injuries are significant markers for IPV whereas injuries to the extremities and abdomen are not as sensitive for IPV [9].

This study found that the victims of IPV were most commonly Black, consistent with previous literature. However, black patients were less likely to be hospitalized for their injuries. Males were more likely to be hospitalized than females. Younger adult women, between the age of 20-40 years are more likely to be victims, and with increasing age there is increased risk of hospitalization. Although we could not distinguish pregnant females from nonpregnant females, IPV is unfortunately commonly seen in preg- nant women, with rates as high as $5 \%$ prior to delivery and $12 \%$ after delivery [10]. Recognition of IPV is important, as homicide is a leading cause of maternal mortality [10]. While current literature often focuses on women, men are equally likely to report IPV when interviewed, particularly in the LGBTQ community [11]. Many studies also lack including men as victims of IPV [11]. This study highlighted one-fourth of IPV-relatd ocular injuries in men, through fire, burns, or being struck by an object.

Literature shows that abuse is not a one time event - there is significant morbidity and mortality from IPV. $40 \%$ of all female homicides are due to an intimate partner [3]. Victims of IPV have increased rates of inflammatory bowel disease and fibromyalgia, somatic symptoms such as chronic pain, and increased rates of suicide and substance use disorder [12].

Limitations of this study are inherent in the database. NEISSAIP only captures patients presenting to the ED and outpatient clinic visits are not incorporated, thus possibly limiting community incidence. Furthermore, NEISS-AIP only encodes one diagnosis for a bodypart and thus an additional, less severe, diagnoses cannot be identified. NEISS does not allow for identification of gender of the partner, which would help identify LGBTQ violence.

Screening and identification of IPV has previously been discussed by the American Academy of Ophthalmologists through the "ASK, ASSESS, and REFER" format, understanding that while identification and assessment is within the scope of clinician practice, patients often need to be referred to social workers for further management [13]. Female patients are more likely to disclose IPV when directly asked by a healthcare provider [14]. Education of ophthalmologists regarding the signs of IPV has been shown to help improve social work referrals, law enforcement involvement, and homegoing safety assessments [15]. Additionally, standardized screening methods to assess a potential history of IPV can be crucial to increase the chance of utilizing an intervention. Screening is especially important in men presenting with injuries suspicious for IPV, as they are often not identified as victims.

\section{Conflicts of Interest}

The authors report no known conflict of interests.

\section{Funding}

No funding was utilized for this research. 


\section{Ethical Statement}

This study contains deidentified data and was deemed IRB exempt.

\section{Bibliography}

1. National Center for Injury Prevention and Control of the Centers for Disease Control and Prevention. The National Intimate Partner and Sexual Violence Survey (NISVS).

2. National Center for Injury Prevention and Control of the Centers for Disease Control and Prevention. The National Intimate Partner and Sexual Violence Survey (NISVS). 2010 Summary Report.

3. Dearwater SR., et al. "Prevalence of intimate partner abuse in women treated at community hospital emergency departments". JAMA 280.5 (1998): 433-438.

4. Telfer MR., et al. "Trends in the aetiology of maxillofacial fractures in the United Kingdom (1977-1987)". British Association of Oral and Maxillofacial Surgeons 29.4 (1991): 250-255.

5. Clark TJ., et al. "Intimate partner violence: an underappreciated etiology of orbital floor fractures". Ophthalmic Plastic and Reconstructive Surgery 30.6 (2014): 508-11.

6. Loder RT and L Momper. "Demographics and fracture patterns of patients presenting to US emergency departments for intimate partner violence". JAAOS Global Research and Reviews 4.2 (2020).

7. Cohen AR., et al. "Intimate partner violence as a mechanism of traumatic ocular injury in women". Canadian Journal of Ophthalmology 54.3 (2019): 355-358.

8. Sheridan DJ and KR Nash. "Acute injury patterns of intimate partner violence victims". Trauma, Violence, and Abuse 8.3 (2007): 281-289.

9. Wu V., et al. "Pattern of physical injury associated with intimate partner violence in women presenting to the emergency department: a systematic review and meta-analysis". Trauma, Violence, and Abuse 11.2 (2010): 71-82.

10. Scribano PV., et al. "The effects of intimate partner violence before, during, and after pregnancy in nurse visited first time mothers". Maternal and Child Health Journal 17.2 (2013): 307318.

11. Dickerson-Amaya N and BM Coston. "Invisibility Is Not Invincibility: The Impact of Intimate Partner Violence on Gay, Bisexual, and Straight Men's Mental Health". American Journal of Men's Health 13.3 (2019): 1557988319849734.
12. Lutgendorf MA. "Intimate Partner Violence and Women's Health". Obstetrics and Gynecology 134.3 (2019): 470-480.

13. Clark TJ SE. "Intimate Partner Violence (IPV) Awareness: ASK, ASSESS, REFER”. April 3, (2015).

14. Crandall ML., et al. "Injury patterns among female trauma patients: recognizing intentional injury". Journal of Trauma 57.1 (2001): 42-45.

15. Dawoud SA., et al. "Detection and Referral of Orbital and Ocular Injuries Associated With Intimate Partner Violence Following an Educational and Screening Initiative in an Emergency Department". JAMA Ophthalmology (2021).

\section{Assets from publication with us}

- Prompt Acknowledgement after receiving the article

- Thorough Double blinded peer review

- Rapid Publication

- Issue of Publication Certificate

- High visibility of your Published work

Website: www.actascientific.com/

Submit Article: www.actascientific.com/submission.php

Email us: editor@actascientific.com

Contact us: +919182824667 